\title{
Electrodialytic per- and polyfluoroalkyl substances (PFASs) removal mechanism for contaminated soil
}

Sörengård, Mattias; Niarchos, Georgios; Jensen, Pernille Erland; Ahrens, Lutz

Published in:

Chemosphere

Link to article, DOI:

10.1016/j.chemosphere.2019.05.088

Publication date:

2019

Document Version

Peer reviewed version

Link back to DTU Orbit

Citation (APA):

Sörengård, M., Niarchos, G., Jensen, P. E., \& Ahrens, L. (2019). Electrodialytic per- and polyfluoroalkyl substances (PFASs) removal mechanism for contaminated soil. Chemosphere, 232, 224-231.

https://doi.org/10.1016/j.chemosphere.2019.05.088

\section{General rights}

Copyright and moral rights for the publications made accessible in the public portal are retained by the authors and/or other copyright owners and it is a condition of accessing publications that users recognise and abide by the legal requirements associated with these rights.

- Users may download and print one copy of any publication from the public portal for the purpose of private study or research.

- You may not further distribute the material or use it for any profit-making activity or commercial gain

- You may freely distribute the URL identifying the publication in the public portal 
1 Electrodialytic per- and polyfluoroalkyl

2 substances (PFASs) removal mechanism

3 for contaminated soil

4

5 Mattias Sörengård ${ }^{a}$, Georgios Niarchos $^{a}$, Pernille Erland Jensen ${ }^{b}$, Lutz Ahrens ${ }^{a}$

6 aSwedish University of Agricultural Sciences (SLU), Department of Aquatic Sciences and Assessment,

7 P. O. Box 7050, SE-750 07 Uppsala, Sweden

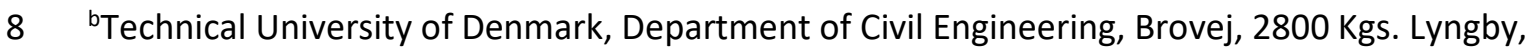

9 Denmark

10

11

12

13

Graphical abstract

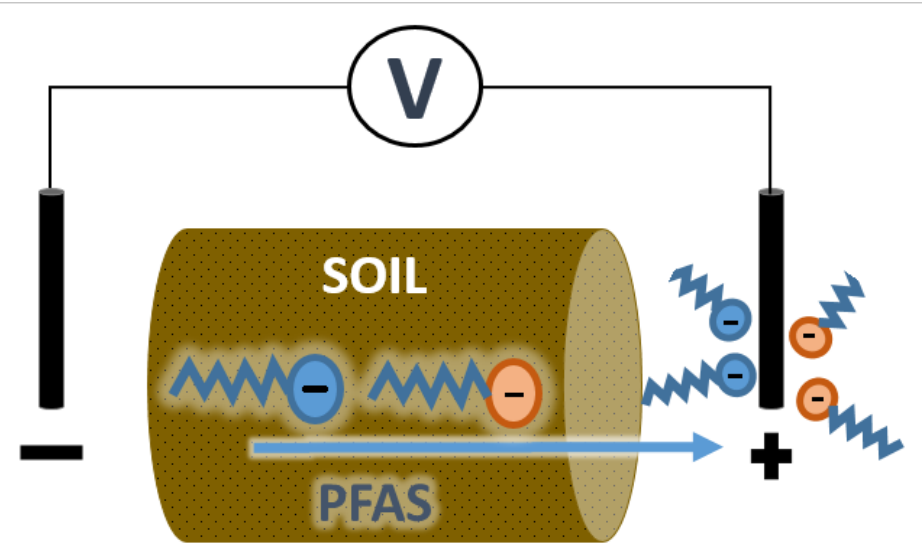




\section{Abstract}

Contamination of soils with per- and polyfluoroalkyl substances (PFASs) is a global problem, in particular at fire-fighter training sites due to the usage of PFAS-containing aqueous fire-fighting foams (AFFFs). In this study, an electrodialytic remediation method was applied for the first time to remove PFASs from contaminated soil. The electrodialytic remediation system was evaluated in a laboratoryscale experiment with current densities of $0.19 \mathrm{~mA} \mathrm{~cm}^{-2}$ and $0.38 \mathrm{~mA} \mathrm{~cm}^{-2}$ over 21 days, using PFAScontaminated soil from a fire-fighter training site at Stockholm Arlanda Airport, Sweden. Of the 23 PFASs targeted, significant $(p<0.05)$ PFAS electromigration towards the anode was observed for $C_{3}-C_{7}$ perfluoroalkyl carboxylates (PFCAs) (PFBA, PFPeA, PFHxA, PFOA) and $\mathrm{C}_{4}, \mathrm{C}_{6}$, and $\mathrm{C}_{8}$ perfluoroalkane sulfonates (PFSAs) (PFBS, PFHxS, PFOS) since these PFASs were predominantly negatively charged. In contrast to the electromigration of the charged PFASs, $\mathrm{N}$-methyl perfluorooctane sulfonamide (MeFOSA), perfluorooctane sulfonamidoacetic acid (FOSAA) and ethyl FOSAA (EtFOSAA) showed significant $(p<0.05)$ transport towards the cathode, which is probably attributed due to electro-osmotic flow of these predominantly neutral PFASs. Mass balance calculations showed that for the shortestchained PFASs (i.e., PFBA, PFPeA, PFHxA, PFBS, and PFHxS), up to $20 \%$ was extracted from the soil to the anolyte, which showed that electrodialytic is a possible in-situ remediation technique for PFAScontaminated soil. 


\section{Introduction}

Contamination of soil and groundwater with per- and polyfluoroalkyl substances (PFASs) can eventually impact drinking water delivery systems, posing a risk to human health (Ahrens, 2011). Recently, several water sources in Japan (Murakami et al., 2009), Germany (Gellrich et al., 2013) and Sweden (Li et al., 2018) have had to be restricted or even shut down because of PFAS residues entering the groundwater and contaminating wells. Particularly high concentrations of PFASs in the aqueous environment and in drinking water have been attributed to the use of PFAS-containing aqueous firefighting foams (AFFF) at fire-fighter training facilities (Baduel et al., 2015), resulting in long-term contamination of the immediate environment originating from contaminated soils (Ahrens et al., 2015;

Filipovic et al., 2015). Thus, there is an urgent need to develop treatment techniques for remediation of soil and groundwater. To date, very few studies have focused on innovative remediation methods for PFAS-contaminated soil. Two studies have shown that PFASs can be stabilized in soil by mixing activated carbon (AC) or cementious materials into the soil (Kupryianchyk et al., 2016; Hale et al., 2017; Sörengård et al., 2019). However, short-chain PFASs have been shown to desorb from AC over time (McCleaf et al., 2017), and long-term studies on stabilization remediation methods are lacking. Another reported remediation method is phytoremediation, where PFASs are extracted from contaminated soil and groundwater through plants (Gobelius et al., 2017), but this method mainly extracts water-soluble shorter-chain PFASs and extraction rates are low, resulting in time-consuming remediation.

A promising remediation method is electrokinetic extraction, a non-interruptive in situ remediation technique that involves applying an electric field to the soil (Acar and Alshawabkeh, 1993; Virkutyte et al., 2002; Yeung and Gu, 2011). Under the induced low current, positively charged ions are transported by electric force and migrate towards the cathode, while negatively charged ions migrate to the anode (i.e., electromigration) (Fig. 1). Electrokinetic extraction has been applied to soil to remove various pollutants, such as heavy metals (Jensen et al., 2007) and various neutral, cationic, and anionic organic contaminants (Guedes et al., 2014; López-Vizcaíno et al., 2017a; Yusni and Tanaka, 2015) (see Table S1 in Supporting Information (SI)). However, to our knowledge, the technology has not previously been 
evaluated for PFASs. PFASs have unique characteristics, being amphiphilic, and most PFASs are charged at typical environmental $\mathrm{pH}$. For example, the acid dissociation constant $\left(p K_{a}\right)$ value of perfluoroalkyl carboxylates (PFCAs) and perfluoroalkane sulfonates (PFSAs) is generally <2 (Du et al., 2014; Rayne et al., 2009), which makes PFASs ideal candidates for electromigration. This is in contrast to most other regulated persistent organic pollutants of concern for soil remediation, which most are neutral under environmental pH (Ren et al., 2018) and therefore not subjectable to electromigration (Chung and Lee, 2007; Ruiz et al., 2014; Gholami et al., 2014).

A crucial aspect of the electrokinetic system is the $\mathrm{pH}$, which can range between 2 to 10 that can affect contaminant solubility and charge. This is mainly due to electrolysis reactions of water at the electrodes, which alkalify the soil adjacent to the cathode and acidify the soil adjacent to the anode (Jensen et al., 2007). Another dominant process in the electrokinetic system in soil is electro-osmotic flow, where water is transported towards the cathode (Acar and Alshawabkeh, 1993), which is particularly efficient in low permeability clay soils (Reddy and Saichek., 2003). Soil constituents, especially clay particles and organic carbon, have dominantly negatively charged surfaces under natural pH (Sposito et al., 1999). The charge neutrality in the soil is therefore maintained by cationic solution ions, such as $\mathrm{H}^{+}, \mathrm{Mg}^{2+}$, and $\mathrm{Ca}^{2+}$ (Sposito, 1998). Because of the relatively higher abundance of cationic solution ions, the dominant ion electromigration vector is towards the cathode, and the higher ion concentration induces an osmotic gradient towards the cathode. Thus, anionic compounds, such as many PFASs, may be influenced by both electromigration and electro-osmosis, with opposing transport vectors, which could be a promising in-situ remediation technique for PFAS-contaminated soil and groundwater.

The aim of this study was to assess, for the first time, the effect of the electrokinetic remediation process on PFASs $(n=23)$ in natural soil contaminated with PFAS-containing AFFFs. The specific objectives of the study were to, i) assess the transport vectors of various PFASs in the electrokinetic system, and ii) determine the distribution of individual PFASs in all phases of the electrokinetic system. 


\section{Material and Methods}

\subsection{Analytical standards}

The targeted PFASs were: $\mathrm{C}_{3}-\mathrm{C}_{11}$ PFCAs (PFBA, PFPeA, PFHxA, PFHpA, PFOA, PFNA, PFDA, PFUnDA, PFDoDA), $C_{4}, C_{6}$, and $C_{8}$ PFSAs (PFBS, PFHxS, PFOS), 6:2 and 8:2 fluorotelomer sulfonic acids (FTSAs) and following $\mathrm{C}_{8}$ perfluorooctane sulfonamides (FOSAs) (FOSA, MeFOSA, EtFOSA), $\mathrm{C}_{8}$ perfluorooctane sulfonamide ethanols (FOSEs) (MeFOSE, EtFOSE), and $C_{8}$ perfluorooctane sulfonamidoacetic acids (FOSAAs) (FOSAA, MeFOSAA, EtFOSAA). In addition, 16 isotopically labeled internal standards (ISs) were included $\left({ }^{13} \mathrm{C}_{4}\right.$-PFBA, ${ }^{13} \mathrm{C}_{2}$-PFHxA, ${ }^{13} \mathrm{C}_{4}$-PFOA, ${ }^{13} \mathrm{C}_{5}$-PFNA, ${ }^{13} \mathrm{C}_{2}$-PFDA, ${ }^{13} \mathrm{C}_{2}$-PFUnDA, ${ }^{13} \mathrm{C}_{2}$-PFDoDA, ${ }^{18} \mathrm{O}_{2}$-PFHxS, ${ }^{13} \mathrm{C}_{4}$-PFOS, ${ }^{13} \mathrm{C}_{8}$-FOSA, $\mathrm{D}_{3}$-MeFOSA, $\mathrm{D}_{5}$-EtFOSA, D $\mathrm{D}_{7}$-MeFOSE, $\mathrm{D}_{9}$-EtFOSE, $\mathrm{D}_{3}$-MeFOSAA, and $\mathrm{D}_{5}$-EtFOSAA). Abbreviation, supplier, and purity of the native PFASs and ISs are listed in Table S2 in SI.

\subsection{Sampling and soil characterization}

In July 2015, composite soil samples were collected using a stainless steel shovel from a depth of 0.10$0.30 \mathrm{~m}$ at a fire-fighter training site known to be contaminated with PFASs (Gobelius et al., 2017) and

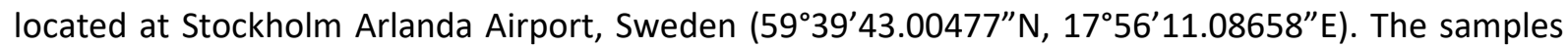
were stored in airtight polypropylene (PP) bags at $4^{\circ} \mathrm{C}$ before the experiments started. The soil texture at sampling consisted of $7 \%$ sand, $34 \%$ silt, and $59 \%$ clay, the soil pH was 6.0 (liquid solid ration (L/S) of 10, $691 \mathrm{pH}$ Meter, Metrohm, Switzerland), and the electrical conductivity was $23 \mu \mathrm{S} \mathrm{cm}^{-1}$ (L/S of 10 , PW 9527, Labassco Hanna instruments, USA). Grain size distribution was estimated by wet sieving (Swedish standardized methodology (SS027123)). The organic carbon content, measured using loss of ignition at $550{ }^{\circ} \mathrm{C}$ for $24 \mathrm{~h}$, was $3.3 \%$. Water content was estimated by weight after freeze-drying ( 7 days) the soil samples. Concentrations of the major soil elements and heavy metals ( $\mathrm{Al}, \mathrm{Ca}, \mathrm{Fe}, \mathrm{K}, \mathrm{Mg}$, $\mathrm{Mn}, \mathrm{Na}, \mathrm{V}, \mathrm{Cr}, \mathrm{Cu}, \mathrm{Ni}, \mathrm{Pb}, \mathrm{Zn}$ ) were measured by inductively coupled plasma-optical emission spectroscopy (ICP-OES) $(n=3)$ according to Danish Standard (DS259), and are shown in Table S3 in SI. The soil elements and heavy metals only measured before the experiment as initial variables and were not assessed after the electrokinetic experiments. 


\subsection{Experimental set-up}

Two electrokinetic experiments were performed, using a three-compartment cell with two different current densities (0.19 and $0.38 \mathrm{~mA} \mathrm{~cm}^{-2}$ ) (Fig. 1) (similar to e.g. Hansen et al., 1999). The middle compartment comprised a hollow cylindrical Plexiglas container (diameter $=8 \mathrm{~cm}$, length $=10 \mathrm{~cm}$ ) and was filled with homogenized PFAS-contaminated soil (0.95 kg wet weight (ww) and $1.2 \mathrm{~kg} w w$, respectively) wetted with deionized water to approximately field capacity ( $22 \%$ water content). The electrodes and two electrolyte compartments were attached to the middle soil compartment using silica gel and exterior metal clamps.

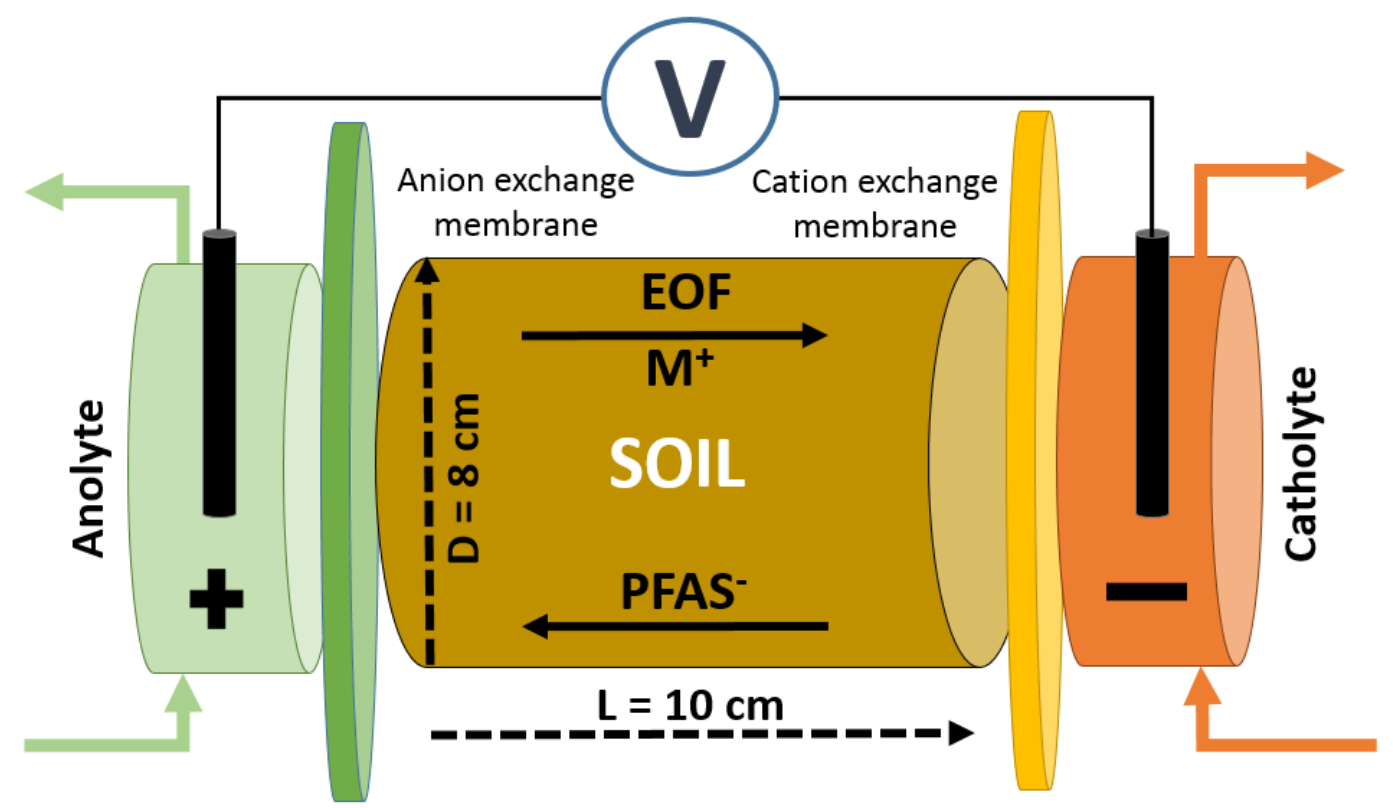

Figure 1. Conceptual schematic of the experimental set-up of the electrodialytic system, including the processes of electroosmotic flow (EOF), electromigration of cationic soil counter-ions $\left(\mathrm{M}^{+}\right)$, and electromigration of anionic PFASs.

The described electrokinetic system set-up is often referred as electrodialytic remediation, where intrusion of electrode products $\left(\mathrm{H}^{+}, \mathrm{OH}^{-}\right)$into the soil is regulated by ion exchange membranes to control the $\mathrm{pH}$ (Ottosen et al., 2000). A selective anion exchange membrane (SUEZ, art. No. AR204SZRA, MKIII, France), was placed between soil and anolyte to prevent hydrogen ions $\left(\mathrm{H}^{+}\right)$ generated at the anode from entering the soil, while a selective cation exchange membrane (Ionics, art. no. CR67HMP, MKIII, France) was placed between the soil and catholyte to prevent hydroxide ions 
$\left(\mathrm{OH}^{-}\right)$generated at the cathode from entering the soil. Each of the electrolytes, consisting of $350 \mathrm{~mL}$ sodium nitrate $\left(\mathrm{NaNO}_{3}, 0.01 \mathrm{M}, \mathrm{VWR}, \geq 99.5 \%\right.$ purity) in Millipore water, was continuously pumped in a closed system to the anode or cathode, using a peristaltic pump $\left(\sim 30 \mathrm{~mL} \mathrm{~min}{ }^{-1}\right)$. A constant direct current (DC) of $10 \mathrm{~mA}$ or $20 \mathrm{~mA}$ from a power supply (Hewlett Packard E3612A) was applied to the soil for 21 days, placing the electrodes in the respective electrolyte. Voltage, $\mathrm{pH}$ and conductivity (the latter two in the electrolyte) were measured daily (Tables S4 and S5 in SI) and, if the $\mathrm{pH}$ was below 1 or above 3 , the electrolyte was adjusted with an appropriate amount of nitric acid $\left(\mathrm{HNO}_{3}, 7 \mathrm{M}, \mathrm{VWR}\right.$, AnalaR NORMAPUR grade) or hydrochloric acid ( $\mathrm{HCl}, 35 \%$, VWR, TECHNICAL grade), respectively (Tables S4 and S5 in SI). The electrodes used were platinum-coated titanium rod electrodes. After the treatment, the electrolytes, ion exchange membranes, and soil (10-11 slices of $0.9-1.0 \mathrm{~cm}$ thickness perpendicular to the electric field) were stored in darkness at $4^{\circ} \mathrm{C}$ in separate sealed polypropylene (PP) bags until analysis. The soil from the $0.19 \mathrm{~mA} \mathrm{~cm}^{-2}$ experiment was analyzed for eight PFASs (PFBA, PFHpA, PFHxA, PFOA, PFBS, PFHxS, PFOS, and FOSA), while the soil from the $0.38 \mathrm{~mA} \mathrm{~cm}^{-2}$ experiment was analyzed for all 23 PFASs in all soil samples, due to an extension of the analytical method. In addition, membranes and electrolytes from the $0.38 \mathrm{~mA} \mathrm{~cm}^{-2}$ experiment were analyzed for all 23 PFASs. The aqueous phase PFASs were measured $(n=2)$ in the electrolytes before and after the experiment, with sampling in both the anolyte and catholyte in the latter case. To compensate for the initial PFAS contamination in the electrolytes (Table S6 in SI), the PFAS concentrations at the beginning of the experiment were subtracted from the end concentrations. Soil samples were characterized for $\mathrm{pH}$, particle size distribution, conductivity, moisture content, carbon content, and organic carbon content. Statistical analysis (ANOVA) was performed using Matlab with a significance level $(\alpha)$ of 0.05 applied to identify significant PFAS concentration changes in the soil column after treatment. When PFAS analysis. 


\subsection{PFAS analysis}

The electrolyte solution (500 $\mu \mathrm{L}$ ) was transferred into a PP Eppendorf tube, and $400 \mu \mathrm{L}$ methanol and $100 \mu \mathrm{L}$ of an IS mixture (concentration (c) $=10 \mathrm{ng} \mathrm{mL}^{-1}$ ) were added. The mixture was then vortexed for $10 \mathrm{~min}$ and filtered (Sartorius, recycled cellulose, $0.45 \mu \mathrm{m}$ ) into a $1.5 \mathrm{~mL}$ auto-injector brown glass vial. The solid samples (i.e., ion exchange membranes and soil) were analyzed using solid-liquid extraction as described elsewhere (Ahrens et al., 2009). In brief, $3.0 \mathrm{~g}$ of freeze-dried (7 days) solid sample were homogenized using a ceramic mortar, spiked with $100 \mu \mathrm{L}$ of an IS mixture (c $=10 \mathrm{ng} \mathrm{mL}^{-}$ $\left.{ }^{1}\right)$ and extracted with solid-liquid extraction using methanol (LiChrosolv, Merck, Germany). The extract was concentrated under a nitrogen gas stream to $500 \mu \mathrm{L}$, and then centrifuged for $10 \mathrm{~min}$ at $3000 \mathrm{rpm}$. The $500 \mu \mathrm{L}$ extract was fortified with $500 \mu \mathrm{L}$ Millipore water in an Eppendorf tube, and $1000 \mu \mathrm{L}$ of $1 \mathrm{M}$ sodium hydroxide ( $\mathrm{NaOH}$, in Millipore water) were added to the extract, which was then vortexed for 15 minutes, centrifuged at $15000 \mathrm{rpm}$ for $15 \mathrm{~min}$, and filtered through $0.45 \mu \mathrm{m}$ recycled cellulose syringe filters (Sartorius, Germany) into $1.5 \mathrm{~mL}$ auto-injector brown glass vials (Eppendorf, Germany).

The instrumental analysis was performed with an ultra-high performance liquid chromatograph coupled to tandem mass spectroscopy (UHPLC-MS/MS) (Quantiva TSQ; Thermo Fisher, MA, USA). The injection volume was $10 \mu \mathrm{L}$ separated on a C18 column (1.7 $\mu \mathrm{m}, 50 \mathrm{~mm}$, Waters). The eluents were methanol and water with $5 \mathrm{mM}$ ammonium acetate, and the eluent gradient was set to $12 \mathrm{~min}$. The isotope dilution method was employed for quantification, using an eight-point calibration curve ranging between 0.01 and $100 \mathrm{ng} \mathrm{mL}^{-1}$. The data were evaluated using $\operatorname{TraceFinder}^{\mathrm{TM}}$ software (Thermo Fisher, MA, USA).

\subsection{Quality control and quality assurance}

The PFAS concentrations in the blanks $(n=3)$ for the solid samples ranged from not detected to 0.57 $\mu \mathrm{gg}^{-1}$ dry weight (PFBA) and those in the blanks for the aqueous samples $(n=2)$ ranged from not detected to $0.18 \mathrm{ng} \mathrm{mL}^{-1}$ (EtFOSAA) (Tables S7 and S8 in SI). The MDLs for PFASs were calculated using average blank concentration $(n=3)$ plus three times standard deviation and, if no PFAS was detected in the blanks, the lowest calibration point was used. The average MDL for all PFASs was $0.21 \mu \mathrm{g} \mathrm{kg}^{-1} \pm$ 
$0.36 \mu \mathrm{g} \mathrm{kg}^{-1}$ for the solid samples and $0.07 \pm 0.14 \mathrm{ng} \mathrm{mL}^{-1}$ (excluding MeFOSE and EtFOSE, which were not detected in the solid or aqueous samples) for the aqueous phase (Tables S7 and S8 in SI). The method recovery was calculated on the losses of IS during sample preparation and matrix effects, and was compared against the calibration curve. On average, the recovery was $84 \% \pm 22 \%$ for individual PFASs in the aqueous phase and $104 \% \pm 34 \%$ for individual PFASs in the solid samples (Table S9 in SI). The average regression coefficient $\left(R^{2}\right)$ of the calibration curves was $>0.99$ in all cases. Measurement (replicate) error for the triplicate soil extractions $(n=10)$ was on average $45 \% \pm 26 \%$ for the individual PFASs, due to the low concentrations for some PFASs, while it was lower for the PFASs found at higher concentrations (e.g., 15\%, 11\%, and 28\% for PFHxS, PFOS, and PFOA respectively) (Table S10 in SI). Although the replicate error was high for some PFASs, the large number of samplings per experiment (30 soil samples per experiment) was considered sufficient to allow significant trends $(p<0.05)$ to be identified. Experimental mass balance recovery (MBR) was calculated for each individual PFAS as:

$\operatorname{MBR}[\%]=\frac{\sum_{i=1}^{i=10} w_{i, \text { soil }} c_{i, \text { soil }}+c_{\text {catholyte }} v_{\text {catholyte }}+c_{\text {anolyte }} v_{\text {anolyte }}+M_{- \text {membrane }}+M_{+ \text {membrane }}}{\sum_{i=1}^{i=10} c_{0, \text { soil }} w_{0, \text { soil }}}$

where $w$ is the soil mass, $i$ is the sample slice from the experiment, $c$ is the individual PFAS concentration, $v$ is the end volume of the electrolytes, and $M$ is the absolute mass on the membranes (Table S11 in SI).

\section{Results and discussion}

\subsection{Performance parameters of the electrodialytic experiment}

The initial soil characteristics, concentrations of major elements, and PFAS concentrations are presented in Table 1. The soil from the fire-fighter training site at Stockholm Arlanda Airport can be characterized as a clay (Fig. S1 in SI), with a relatively low carbon content of $3.3 \% \pm 0.12 \%$, conductivity of $23 \mu \mathrm{S} \mathrm{cm}^{-2}$, and relatively low buffering capacity of $2.2 \% \pm 1.2 \% \mathrm{CaCO}_{3}$. To keep the current constant, an average voltage of $8.5 \mathrm{~V} \pm 3.0 \mathrm{~V}$ and $20 \mathrm{~V} \pm 3.3 \mathrm{~V}$ was needed for the $0.19 \mathrm{~mA} \mathrm{~cm}^{-2}$ and $0.38 \mathrm{~mA} \mathrm{~cm}$

${ }^{2}$ experiments, respectively (Tables $\mathrm{S} 4$ and $\mathrm{S} 5$ in $\mathrm{SI}$ ). The soil variables measured in the $0.38 \mathrm{~A} \mathrm{~cm}^{-2}$ 
experiment (Table 1) were similar to those determined in previous electrodialytic experiments (Jensen et al., 2007). After 21 days of the experiment, the pH did not drastically change throughout the soil column. However, although the $\mathrm{pH}$ was controlled with the anion exchange membrane at the anode, at $2-3 \mathrm{~cm}$ distance from the anode the $\mathrm{pH}$ decreased to below $\mathrm{pH} 3.0$, whereas the remaining soil had $\mathrm{pH}$ of around 4 (Fig. 2A). The latter was $2 \mathrm{pH}$ units bellow the initial $\mathrm{pH}$, a change that can have large importance since organic pollutants ion state is determined by the $\mathrm{pH}$ where e.g. FOSA included in this study has a reported $p K_{a}$ value of 6.2-6.5 (Rayne and Forest, 2009), and hence it is not ionized under the current experimental condition. Previous studies have reported a similar finding and have attributed it to water splitting at the membrane or leakage of the small hydrogen ions (1 Da) through the membrane (Hansen et al., 1999; Ottosen et al., 2000). Electrical conductivity was, as expected, inversely correlated with $\mathrm{pH}$ and was $220-630 \mu \mathrm{S} \mathrm{cm}-1$ at the anode $(0-3 \mathrm{~cm})$ and $28-65 \mu \mathrm{S} \mathrm{cm}^{-1}$ with increasing distance from the anode $(4-10 \mathrm{~cm})$ (Fig. 2B, Fig. S2 in SI). The water content was higher at the cathode (23\%) and gradually decreased towards the anode (21\%) (Fig. 2C). The catholyte volume increased from 350 to $590 \mathrm{~mL}$ after 21 days, whereas the anolyte volume decreased from 350 to 190 $\mathrm{mL}$ in the same period. This net water transport towards the cathode indicates electro-osmotic flow towards the cathode. The soil organic carbon content, an important soil component, showed a transport vector towards the anode, which is opposite to the transport along the water flow (Fig. 2D). This can be explained by the fact that soil organic carbon is dominantly negatively charged under environmental pH because of dissociation of phenol and carboxylic groups (Kinniburgh et al., 1999), and hence can be affected by electromigration. 
Table 1. Soil characteristics $(n=3)$, soil elements [ $\left.\mathrm{mg} \mathrm{kg}^{-1}\right](n=3)$, and individual PFAS concentrations [ $\left.\mu \mathrm{gg}^{-1}\right]$ in the soil samples at the beginning of the experiment $(n=2)^{\text {a }}$.

\begin{tabular}{|c|c|c|c|c|c|c|c|}
\hline Soil characteristics & & \multicolumn{2}{|c|}{$\begin{array}{l}\text { Initial soil } \\
\text { metal } \\
\text { composition } \\
{\left[\mathrm{mg} \mathrm{kg}^{-1}\right]}\end{array}$} & \multicolumn{2}{|c|}{$\begin{array}{l}\text { Initial PFCA and } \\
\text { PFSA } \\
\text { concentrations } \\
{\left[\mu \mathrm{kg}^{-1}\right]}\end{array}$} & \multicolumn{2}{|c|}{$\begin{array}{l}\text { Initial FTSA, FOSA, FOSE, } \\
\text { FOSAA concentrations } \\
{\left[\mu \mathrm{g} \mathrm{kg}^{-1}\right]}\end{array}$} \\
\hline Sand [\%] & 7 & $\mathrm{Fe}$ & 37000 & PFBA & 1.1 & 6:2 FTSA & 0.45 \\
\hline Silt [\%] & 34 & Al & 25000 & PFPeA & 2.6 & 8:2 FTSA & $<0.085$ \\
\hline Clay [\%] & 59 & Mg & 6100 & PFHxA & 1.3 & FOSA & 0.64 \\
\hline Organic carbon [\%] & 3.3 & K & 4200 & PFHpA & 0.99 & MeFOSA & $<0.0017$ \\
\hline Water content [\%] & 22 & $\mathrm{Ca}$ & 3500 & PFOA & 1.0 & EtFOSA & 0.21 \\
\hline $\mathrm{CaCO}_{3}[\%]$ & 2.2 & $M n$ & 390 & PFNA & $<0.33$ & MeFOSE & $<0.17$ \\
\hline Conductivity $\left[\mu \mathrm{S} \mathrm{cm}^{-1}\right]$ & 23 & $\mathbf{P}$ & 270 & PFDA & 0.11 & EtFOSE & $<0.83$ \\
\hline \multirow[t]{6}{*}{ pH } & 6.0 & $\mathrm{Na}$ & 300 & PFUnDA & 0.068 & FOSAA & $<0.070$ \\
\hline & & & 88 & PFDoDA & 0.054 & MeFOSAA & 0.0175 \\
\hline & & & & PFBS & 0.34 & EtFOSAA & 0.21 \\
\hline & & & & PFHxS & 3.4 & & \\
\hline & & & & PFOS & 28 & & \\
\hline & & & & PFDS & 0.025 & & \\
\hline
\end{tabular}
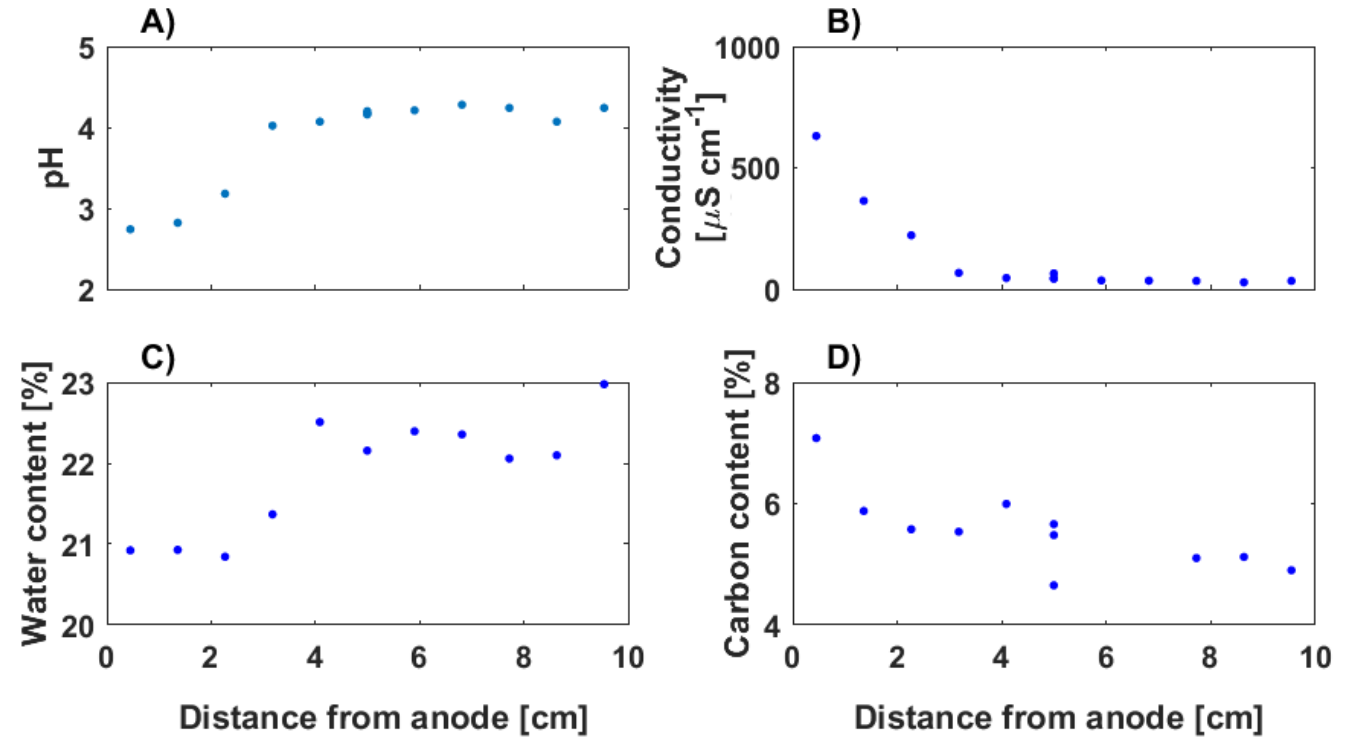

Figure 2. Electrodialytic remediation performance in the soil in the $0.38 \mathrm{~mA} \mathrm{~cm}^{-2}$ experiment, shown as changes in A) $\mathrm{pH}, \mathrm{B}$ ) conductivity $\left.\left[\mu \mathrm{S} \mathrm{cm}^{-1}\right], \mathrm{C}\right)$ water content [\%], and D) organic carbon content [\%] after 21 days. 


\subsection{Electromigration of PFASs}

In the untreated soil, 16 of the 23 individual PFASs were detected (all except PFNA, MeFOSA, EtFOSA, MeFOSE, EtFOSE, FOSAA, and 8:2 FTSA) (Table 1, Table S5 in SI). However, after the 21-day experiment with $0.38 \mathrm{~mA} \mathrm{~cm}^{-2}$, MeFOSA, FOSAA, and 8:2 FTSA were detected at low concentrations, while EtFOSE was not detected, which can be explained by low concentration levels, close to the MDL (Figs. S3-S5 in SI). The majority of negatively charged PFASs were observed to be significantly transported towards the anode ( $p<0.05$, ANOVA), although the net transport vector of electro-osmotic flow was towards the cathode (Figs. 2 and 3). A significant trend was found for PFBA, PFPeA, PFHxA, PFOA, PFBS, PFHxS, and PFOS using $0.19 \mathrm{~mA} \mathrm{~cm}^{-2}$ ( $p<0.05$, ANOVA), and for PFHpA, PFHxA, PFOA, PFHxS, PFOS, and 8:2 FTSA using $0.38 \mathrm{~mA} \mathrm{~cm}^{-2}(p<0.05$, ANOVA) (Fig. 3). PFOS is mainly removed from close to the cathode and this can be explained by PFAS having 1-2 orders om magnitude higher concentration than the other PFASs These results indicate that the dominant treatment mechanism is electrokinetic transport, which is in agreement with findings in previous studies on anionic organic compounds in electrodialytic systems, where the negatively charged methyl orange and the pesticides 2,4-D and chlorosulfuron also were transported towards the anode (Souza et al., 2017; Yusni and Tanaka, 2015). The other PFASs (i.e., PFHpA, PFDA, PFUnDA, PFDoDA, PFDS, and 6:2 FTSA), which were predominantly charged under the experimental pH conditions, did not show a significant gradient over the soil column in the $0.38 \mathrm{~mA} \mathrm{~cm}^{-2}$ experiment (Figs. S3 and S4 in SI). These PFASs were detected close to their MDL and were predominantly longer-chain PFASs. Previous studies have been shown that longer-chain PFASs adsorb much more strongly to soil, sediments and soil organic matter than short-chain PFASs (Higgins and Luthy, 2006; Ahrens et al., 2010; Campos Pereira et al., 2018), and strong sorption could explain the immobility of the longer-chain PFASs in the present study. Noteworthy was that PFHpA, with physiochemical similarities to PFHxA and PFOA, accumulated at the cathode (S3 in the SI), however, the trend was not significant $(p<0.05)$.

In contrast to the electromigration of the charged PFASs, the predominantly neutral PFASs (i.e., MeFOSA, FOSAA, and EtFOSAA) showed significant transport towards the cathode. The functional 
group of MeFOSA has been reported to be neutral at the experimental pH (Rayne and Forest, 2009),

256 however to the best of the author's knowledge, the $p K_{a}$ of FOSAA, and EtFOSAA has not been

257 determined in the scientific literature. The transport of the predominantly neutral PFASs can be possibly explained by the electro-osmotic flow. Similarly, previous studies have reported trends towards the cathode for neutral organic contaminants, e.g., petroleum hydrocarbons (Lee et al., 2016), trichloroethylene (Chung and Lee, 2007), 2,4,6-trichlorophenol (Ruiz et al., 2014) and
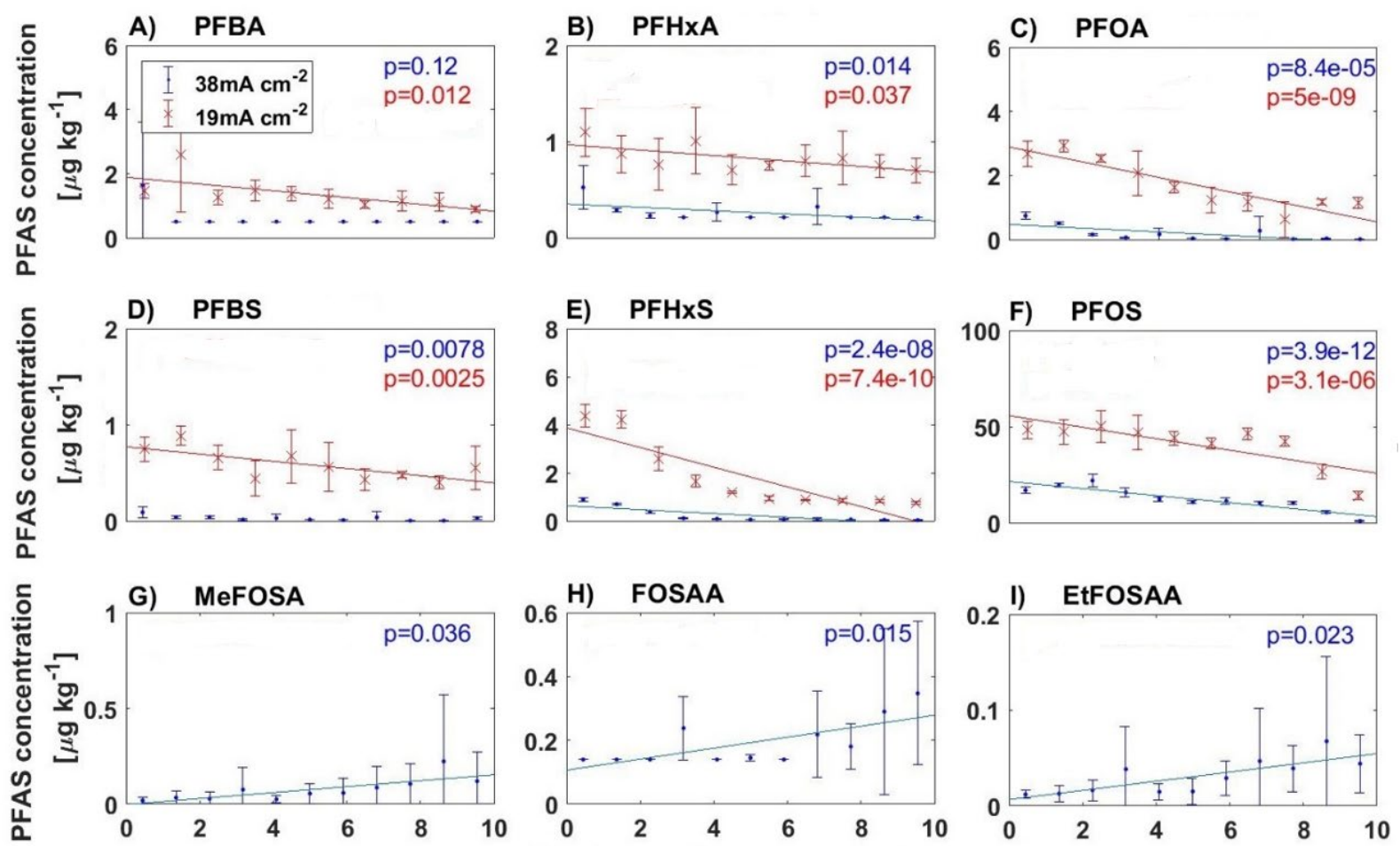

Distance from anode $[\mathrm{cm}]$

Figure 3. Spatial concentration distributions and corresponding significant (ANNOVA, Matlab) linear regression lines for the PFCAs (A-C), PFSAs (D-F), MeFOSA (G), and FOSAAs (H-I) measured in the soil parallel to the electric field applying $0.19 \mathrm{~mA}$ $\mathrm{cm}^{-2}$ (red) and $0.38 \mathrm{~mA} \mathrm{~cm}^{-2}$ (blue). For concentrations below the method detection limit (MDL), a value of MDL/2 was used. Error bars are the standard deviation of triplicates.

Comparing the impact of the two different current densities revealed that the lower current of 0.19 $\mathrm{mA} \mathrm{cm}{ }^{-2}$ resulted in consistently steeper gradients for some shorter-chain PFASs (i.e., PFBA, PFOA, PFBS, and PFHXS) towards the cathode than the higher current of $0.38 \mathrm{~mA} \mathrm{~cm}^{-2}$. This indicates that 
higher current does not necessarily result in better PFAS transport, which makes the remediation technique more cost-efficient. However, the concentrations of most PFASs in soil were lower in the $0.38 \mathrm{~mA} \mathrm{~cm}^{-2}$ experiment than in the $0.19 \mathrm{~mA} \mathrm{~cm}^{-2}$ experiment, which indicates higher accumulation of PFASs in the membrane or in the electrolyte when using higher currents. In future studies, more mass balance comparisons using varying currents are needed to confirm and optimize these findings in order to reach a cost efficient remediation for the field scale.

\subsection{Mass balance distribution of PFASs in the electrodialytic system} The mass balance of PFASs in the electrodialytic system in the $0.38 \mathrm{~mA} \mathrm{~cm}{ }^{-2}$ experiment was heterogeneous (Fig. 4). In general, there was a difference between the short-chain and long-chain PFASs. The shorter-chain PFASs were to a large extent distributed either in the anolyte (2-26\% of PFBA, PFPeA, PFHxA, PFBS, and PFHxS mass distribution) or on the anion exchange membrane (12-78\% of PFBA, PFPeA, PFHxA, PFBS, and PFHxS mass distribution). This means that substantial amounts of the short-chain PFASs were removed from the soil. On the other hand, the longer-chain PFASs (i.e., PFOS and PFOA) were transported towards the anode (Fig. 3), but did not pass over the cation exchange membrane ( $<$ LOQ-1.0 \% of PFOS and PFOA mass distribution) into the electrolyte. The perfluorocarbon chain length is strongly linearly correlated to physiochemical properties such as molecular weight, octanol water partitioning coefficient (log Kow) (Rostvall et al., 2018), hence these results could be transferred to other organic micropollutants.

For PFASs which are concentrated in the aqueous phase of the electrolyte, conventional remediation methods can potentially be applied for removal or destruction (Arias et al., 2015). At the cathode, only a few PFASs were accumulated (i.e., MeFOSA, FOSAA, EtFOSAA) (Fig. 3). However, the mass balance calculations comparing the total mass of PFASs before and after the experiment (Equation 1) showed a low average recovery of $53 \pm 46 \%$ (excluding MeFOSA as an outlier, Table S8 in SI). This high mass balance recovery can be explained by some individual PFAS concentrations lying close to MDL and by measurement uncertainty due to the high composition of ions, which can cause matrix effects. In general, the shorter-chained PFCAs (PFBA, PFPeA, PFHxA and PFHpA) and PFSAs (PFBS and PFHxS) had 
(PFOA, PFDA, PFUnDA and PFDoDA) and PFSAs (PFOS and PFDS) (on average $59 \%$ and $70 \%$, respectively), which remained in the soil to a higher extent (Fig. 4). The short chain PFASs were small enough to transferred through the anion exchange membrane into the electrolyte, and a possible source of losses of the short-chain PFASs was that they could have been subjected to degradation on the anode, as shown in previous studies using electrode degradation (Carter and Farrell, 2008). Electro-

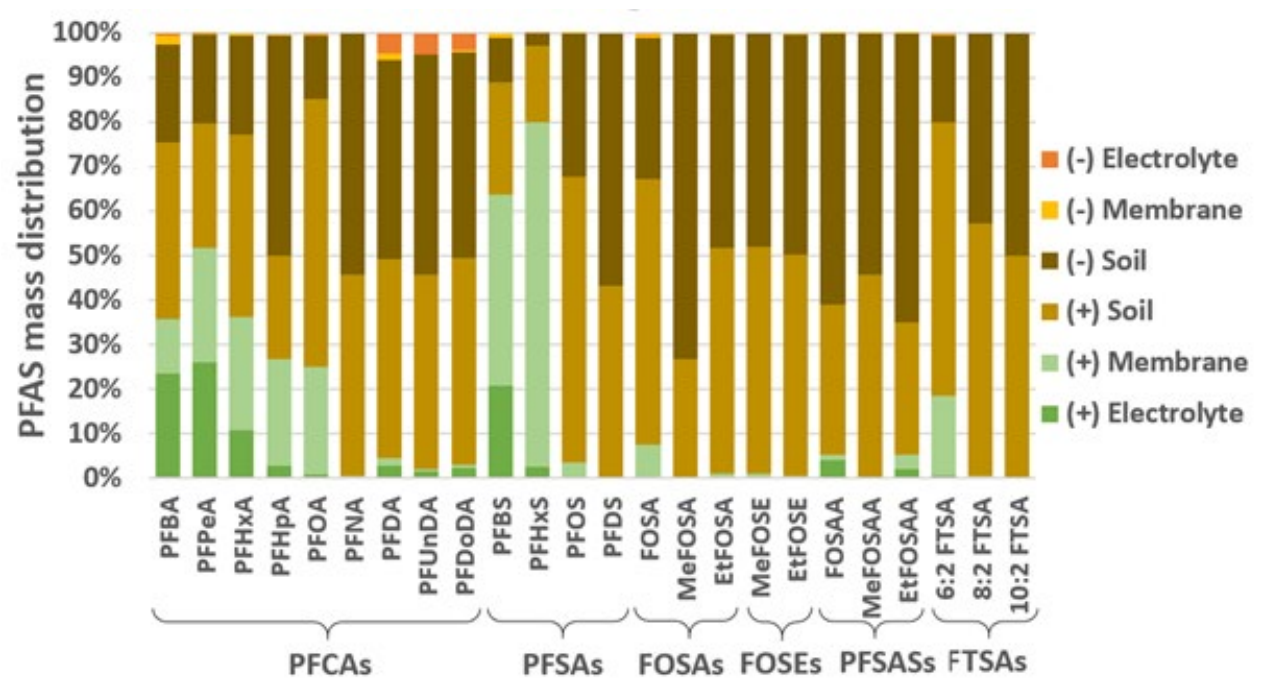

Figure 4. Mass distribution of individual PFASs between the electrolytes, ion exchange membranes, and soil (see Fig. 1) after 21 days of applying a current of $0.38 \mathrm{~mA} \mathrm{~cm}^{-2}$. The soil is represented by slices of $5 \mathrm{~cm}$ closest to the cathode ((-) Soil) and slices of $5 \mathrm{~cm}$ closest to the anode $((+)$ Soil).

Overall, this study showed that electrokinetic system supports a promising removal mechanism for the 
techniques environmental relevance because the vast number of PFAS homologues with over 4700 on the global market (Boston et al., 2019), and variety of anionic, cationic, zwitterionic and neutral PFAS found in e.g. AFFFs (Baduel et al., 2015; Barzen-Hanson et al., 2017; Munoz et al., 2018; Zhi and Liu, 2018).

Ultimately, the results indicate that the technique for PFAS removal can be mature for in-situ pilotscale trial since field-scale electrokinetic remediation methods of soil and groundwater already have been developed for field-scale with success on other contaminants e.g. arsenic, copper, lead and chromium (Kim et al., 2011, 2012; Jeon et al., 2015) and herbicides (López-Vizcaíno et al., 2017). For the future environmental remediation relevance, the authors are raising the following future research challenges: (i) determining if PFASs can be removed sufficiently with longer remediation times, (ii) validation and analysis on more varieties of PFASs found in contaminated soils (e.g. by total oxidizable precursor assays (Houtz and Sedlak, 2012) or total organic fluorine (Yeung et al., 2013)) (iii) determining how long a remediation would take to reach sufficient levels and estimating the associated energy costs, and (iv) if the system can be designed without or with another anion exchange membrane so that the larger PFASs (e.g. PFOS) can be transferred to the electrolyte phase, which in the field scale is advantageous since the electrolyte phase can be pumped out from the ground and further treated in the aqueous phase (Arias et al., 2015).

\section{Supporting Information}

Supporting Information is available free of charge on the... Figures S1-S5 and Tables S1-S11 are available.

\section{Acknowledgements}

This work was supported by the project PFAS-PURE from VINNOVA (2015-03561). 


\section{References}

Acar, Y.B., Alshawabkeh, A.N., 1993. Principles of electrokinetic remediation. Environ. Sci. Technol. 27, 2638-2647. https://doi.org/10.1021/es00049a002

Ahrens, L., 2011. Polyfluoroalkyl compounds in the aquatic environment: a review of their occurrence and fate. J. Environ. Monit. 13, 20-31. https://doi.org/10.1039/COEM00373E

Ahrens, L., Felizeter, S., Sturm, R., Xie, Z., Ebinghaus, R., 2009. Polyfluorinated compounds in waste water treatment plant effluents and surface waters along the River Elbe, Germany. Mar. Pollut. Bull. 58, 1326-1333. https://doi.org/10.1016/j.marpolbul.2009.04.028

Ahrens, L., Norström, K., Viktor, T., Cousins, A.P., Josefsson, S., 2015. Stockholm Arlanda Airport as a source of per-and polyfluoroalkyl substances to water, sediment and fish. Chemosphere 129, 33-38. https://doi.org/10.1016/j.chemosphere.2014.03.136

Ahrens, L., Taniyasu, S., Yeung, L.W.Y., Yamashita, N., Lam, P.K.S., Ebinghaus, R., 2010. Distribution of polyfluoroalkyl compounds in water, suspended particulate matter and sediment from Tokyo Bay, Japan. Chemosphere 79, 266-272. https://doi.org/10.1016/j.chemosphere.2010.01.045

Arias, E., Mallavarapu, M., Naidu, R., 2015. Treatment technologies for aqueous perfluorooctanesulfonate (PFOS) and perfluorooctanoate (PFOA): A critical review with an emphasis on field testing. Environ. Technol. Innov. 4, 168-181. https://doi.org/10.1016/j.eti.2015.06.001

Baduel, C., Paxman, C.J., Mueller, J.F., 2015. Perfluoroalkyl substances in a firefighting training ground (FTG), distribution and potential future release. J. Hazard. Mater. 296, 46-53. https://doi.org/10.1016/j.jhazmat.2015.03.007

Barzen-Hanson, K.A., Roberts, S.C., Choyke, S., Oetjen, K., McAlees, A., Riddell, N., McCrindle, R., Ferguson, P.L., Higgins, C.P., Field, J.A., 2017. Discovery of 40 Classes of Per- and Polyfluoroalkyl Substances in Historical Aqueous Film-Forming Foams (AFFFs) and AFFFImpacted Groundwater. Environ. Sci. Technol. 51, 2047-2057. https://doi.org/10.1021/acs.est.6b05843

Boston, C.M., Banacos, N., Heiger-Bernays, W., 2019. Per- and Polyfluoroalkyl Substances: A National Priority for Safe Drinking Water. Public Health Rep. Wash. DC 1974 134, 112-117. https://doi.org/10.1177/0033354919826567

Campos Pereira, H., Ullberg, M., Kleja, D.B., Gustafsson, J.P., Ahrens, L., 2018. Sorption of perfluoroalkyl substances (PFASs) to an organic soil horizon - Effect of cation composition and $\mathrm{pH}$. Chemosphere 207, 183-191. https://doi.org/10.1016/j.chemosphere.2018.05.012

Carter, K.E., Farrell, J., 2008. Oxidative destruction of perfluorooctane sulfonate using boron-doped diamond film electrodes. Environ. Sci. Technol. 42, 6111-6115. https://doi.org/10.1021/es703273s

Chung, H.I., Lee, M., 2007. A new method for remedial treatment of contaminated clayey soils by electrokinetics coupled with permeable reactive barriers. Electrochimica Acta, ELECTROKINETIC REMEDIATION METHODS OF REMEDIATION OF SOILS AND GROUND WATERS 52, 3427-3431. https://doi.org/10.1016/j.electacta.2006.08.074

Du, Z., Deng, S., Bei, Y., Huang, Q., Wang, B., Huang, J., Yu, G., 2014. Adsorption behavior and mechanism of perfluorinated compounds on various adsorbents-A review. J. Hazard. Mater. 274, 443-454. https://doi.org/10.1016/j.jhazmat.2014.04.038

Filipovic, M., Woldegiorgis, A., Norström, K., Bibi, M., Lindberg, M., Österås, A.-H., 2015. Historical usage of aqueous film forming foam: A case study of the widespread distribution of perfluoroalkyl acids from a military airport to groundwater, lakes, soils and fish. Chemosphere 129, 39-45. https://doi.org/10.1016/j.chemosphere.2014.09.005

Gellrich, V., Brunn, H., Stahl, T., 2013. Perfluoroalkyl and polyfluoroalkyl substances (PFASs) in mineral water and tap water. J. Environ. Sci. Health - Part ToxicHazardous Subst. Environ. Eng. 48, 129-135. https://doi.org/10.1080/10934529.2013.719431 
Gholami, M., Kebria, D.Y., Mahmudi, M., 2014. Electrokinetic remediation of perchloroethylenecontaminated soil. Int. J. Environ. Sci. Technol. 11, 1433-1438. https://doi.org/10.1007/s13762-014-0555-6

Gobelius, L., Lewis, J., Ahrens, L., 2017. Plant Uptake of Per- and Polyfluoroalkyl Substances at a Contaminated Fire Training Facility to Evaluate the Phytoremediation Potential of Various Plant Species. Environ. Sci. Technol. 51, 12602-12610. https://doi.org/10.1021/acs.est.7b02926

Guedes, P., Mateus, E.P., Couto, N., Rodríguez, Y., Ribeiro, A.B., 2014. Electrokinetic remediation of six emerging organic contaminants from soil. Chemosphere 117, 124-131. https://doi.org/10.1016/j.chemosphere.2014.06.017

Hale, S.E., Arp, H.P.H., Slinde, G.A., Wade, E.J., Bjørseth, K., Breedveld, G.D., Straith, B.F., Moe, K.G., Jartun, M., Høisæter, A.., 2017. Sorbent amendment as a remediation strategy to reduce PFAS mobility and leaching in a contaminated sandy soil from a Norwegian firefighting training facility. Chemosphere 171, 9-18. https://doi.org/10.1016/j.chemosphere.2016.12.057

Hansen, H.K., Ottosen, L.M., Hansen, L., Kliem, B.K., Villumsen, A., Bech-Nielsen, G., 1999. Electrodialytic remediation of soil polluted with heavy metals. Key parameters for optimization of the process. Chem. Eng. Res. Des. 77, 218-222. https://doi.org/10.1205/026387699526124

Higgins, C.P., Luthy, R.G., 2006. Sorption of Perfluorinated Surfactants on Sediments ${ }^{\dagger}$. Environ. Sci. Technol. 40, 7251-7256. https://doi.org/10.1021/es061000n

Houtz, E.F., Sedlak, D.L., 2012. Oxidative conversion as a means of detecting precursors to perfluoroalkyl acids in urban runoff. Environ. Sci. Technol. 46, 9342-9349. https://doi.org/10.1021/es302274g

Jensen, P.E., Ottosen, L.M., Harmon, T.C., 2007. The effect of soil type on the electrodialytic remediation of lead-contaminated soil. Environ. Eng. Sci. 24, 234-244. https://doi.org/10.1089/ees.2005.0122

Jeon, E.-K., Jung, J.-M., Kim, W.-S., Ko, S.-H., Baek, K., 2015. In situ electrokinetic remediation of As-, $\mathrm{Cu}$-, and $\mathrm{Pb}$-contaminated paddy soil using hexagonal electrode configuration: a full scale study. Environ. Sci. Pollut. Res. 22, 711-720. https://doi.org/10.1007/s11356-014-3363-0

Kim, B.-K., Baek, K., Ko, S.-H., Yang, J.-W., 2011. Research and field experiences on electrokinetic remediation in South Korea. Sep. Purif. Technol., Scientific Advances and Innovative Applications in Electrokinetic Remediation 79, 116-123. https://doi.org/10.1016/j.seppur.2011.03.002

Kim, W.-S., Park, G.-Y., Kim, D.-H., Jung, H.-B., Ko, S.-H., Baek, K., 2012. In situ field scale electrokinetic remediation of multi-metals contaminated paddy soil: Influence of electrode configuration. Electrochimica Acta, EREM 2011 + ISEE'Cap 2011 + EMRS 2011 86, 89-95. https://doi.org/10.1016/j.electacta.2012.02.078

Kinniburgh, D.G., van Riemsdijk, W.H., Koopal, L.K., Borkovec, M., Benedetti, M.F., Avena, M.J., 1999. Ion binding to natural organic matter: competition, heterogeneity, stoichiometry and thermodynamic consistency. Colloids Surf. Physicochem. Eng. Asp. 151, 147-166. https://doi.org/10.1016/S0927-7757(98)00637-2

Kupryianchyk, D., Hale, S.E., Breedveld, G.D., Cornelissen, G., 2016. Treatment of sites contaminated with perfluorinated compounds using biochar amendment. Chemosphere, Biochars multifunctional role as a novel technology in the agricultural, environmental, and industrial sectors 142, 35-40. https://doi.org/10.1016/j.chemosphere.2015.04.085

Lee, J.-Y., Kwon, T.-S., Park, J.-Y., Choi, S., Kim, E.J., Lee, H.U., Lee, Y.-C., 2016. Electrokinetic (EK) removal of soil co-contaminated with petroleum oils and heavy metals in three-dimensional (3D) small-scale reactor. Process Saf. Environ. Prot. 99, 186-193. https://doi.org/10.1016/j.psep.2015.10.015

Li, Y., Fletcher, T., Mucs, D., Scott, K., Lindh, C.H., Tallving, P., Jakobsson, K., 2018. Half-lives of PFOS, PFHXS and PFOA after end of exposure to contaminated drinking water. Occup. Environ. Med. 75, 46-51. https://doi.org/10.1136/oemed-2017-104651 
Liu, Y., Chen, S., Quan, X., Yu, H., Zhao, H., Zhang, Y., 2015. Efficient Mineralization of Perfluorooctanoate by Electro-Fenton with $\mathrm{H} 2 \mathrm{O} 2$ Electro-generated on Hierarchically Porous Carbon. Environ. Sci. Technol. 49, 13528-13533. https://doi.org/10.1021/acs.est.5b03147 López-Vizcaíno, R., Risco, C., Isidro, J., Rodrigo, S., Saez, C., Cañizares, P., Navarro, V., Rodrigo, M.A., 2017a. Scale-up of the electrokinetic fence technology for the removal of pesticides. Part I: Some notes about the transport of inorganic species. Chemosphere 166, 540-548. https://doi.org/10.1016/j.chemosphere.2016.09.113

López-Vizcaíno, R., Risco, C., Isidro, J., Rodrigo, S., Saez, C., Cañizares, P., Navarro, V., Rodrigo, M.A., 2017b. Scale-up of the electrokinetic fence technology for the removal of pesticides. Part II: Does size matter for removal of herbicides? Chemosphere 166, 549-555. https://doi.org/10.1016/j.chemosphere.2016.09.114

McCleaf, P., Englund, S., Östlund, A., Lindegren, K., Wiberg, K., Ahrens, L., 2017. Removal efficiency of multiple poly- and perfluoroalkyl substances (PFASs) in drinking water using granular activated carbon (GAC) and anion exchange (AE) column tests. Water Res. 120, 77-87. https://doi.org/10.1016/j.watres.2017.04.057

Munoz, G., Ray, P., Mejia-Avendaño, S., Vo Duy, S., Tien Do, D., Liu, J., Sauvé, S., 2018. Optimization of extraction methods for comprehensive profiling of perfluoroalkyl and polyfluoroalkyl substances in firefighting foam impacted soils. Anal. Chim. Acta 1034, 74-84. https://doi.org/10.1016/j.aca.2018.06.046

Murakami, M., Kuroda, K., Sato, N., Fukushi, T., Takizawa, S., Takada, H., 2009. Groundwater Pollution by Perfluorinated Surfactants in Tokyo. Environ. Sci. Technol. 43, 3480-3486. https://doi.org/10.1021/es803556w

Ottosen, L.M., Hansen, H.K., Hansen, C.B., 2000. Water splitting at ion-exchange membranes and potential differences in soil during electrodialytic soil remediation. J. Appl. Electrochem. 30, 1199-1207. https://doi.org/10.1023/A:1026557830268

Rayne, S., Forest, K., 2009. A new class of perfluorinated acid contaminants: primary and secondary substituted perfluoroalkyl sulfonamides are acidic at environmentally and toxicologically relevant pH values. J. Environ. Sci. Health Part A Tox. Hazard. Subst. Environ. Eng. 44, 13881399. https://doi.org/10.1080/10934520903217278

Rayne, S., Forest, K., Friesen, K.J., 2009. Computational approaches may underestimate pKa values of longer-chain perfluorinated carboxylic acids: Implications for assessing environmental and biological effects. J. Environ. Sci. Health - Part ToxicHazardous Subst. Environ. Eng. 44, 317326. https://doi.org/10.1080/10934520802659620

Reddy Krishna R., Saichek Richard E., 2003. Effect of Soil Type on Electrokinetic Removal of Phenanthrene Using Surfactants and Cosolvents. J. Environ. Eng. 129, 336-346. https://doi.org/10.1061/(ASCE)0733-9372(2003)129:4(336)

Ren, X., Zeng, G., Tang, L., Wang, J., Wan, J., Liu, Y., Yu, J., Yi, H., Ye, S., Deng, R., 2018. Sorption, transport and biodegradation - An insight into bioavailability of persistent organic pollutants in soil. Sci. Total Environ. 610-611, 1154-1163. https://doi.org/10.1016/j.scitotenv.2017.08.089

Rostvall, A., Zhang, W., Dürig, W., Renman, G., Wiberg, K., Ahrens, L., Gago-Ferrero, P., 2018. Removal of pharmaceuticals, perfluoroalkyl substances and other micropollutants from wastewater using lignite, Xylit, sand, granular activated carbon (GAC) and GAC+Polonite ${ }^{\circledR}$ in column tests - Role of physicochemical properties. Water Res. 137, 97-106. https://doi.org/10.1016/j.watres.2018.03.008

Ruiz, C., Mena, E., Cañizares, P., Villaseñor, J., Rodrigo, M.A., 2014. Removal of 2,4,6-Trichlorophenol from Spiked Clay Soils by Electrokinetic Soil Flushing Assisted with Granular Activated Carbon Permeable Reactive Barrier. Ind. Eng. Chem. Res. 53, 840-846. https://doi.org/10.1021/ie4028022

Sörengård, M., Kleja, D.B., Ahrens, L., 2019. Stabilization and solidification remediation of soil contaminated with poly- and perfluoroalkyl substances (PFASs). J. Hazard. Mater. 367, 639646. https://doi.org/10.1016/j.jhazmat.2019.01.005 
Souza, F.L., Sáez, C., Lanza, M.R.V., Cañizares, P., Rodrigo, M.A., 2017. Removal of chlorsulfuron and 2,4-D from spiked soil using reversible electrokinetic adsorption barriers. Sep. Purif. Technol. 178, 147-153. https://doi.org/10.1016/j.seppur.2017.01.030

Sposito, G., 1998. On points of zero charge. Environ. Sci. Technol. 32, 2815-2819. https://doi.org/10.1021/es9802347

Sposito, G., Skipper, N.T., Sutton, R., Park, S.-H., Soper, A.K., Greathouse, J.A., 1999. Surface geochemistry of the clay minerals. Proc. Natl. Acad. Sci. U. S. A. 96, 3358-3364. https://doi.org/10.1073/pnas.96.7.3358

Virkutyte, J., Sillanpää, M., Latostenmaa, P., 2002. Electrokinetic soil remediation - critical overview. Sci. Total Environ. 289, 97-121. https://doi.org/10.1016/S0048-9697(01)01027-0

Yeung, A.T., Gu, Y.-Y., 2011. A review on techniques to enhance electrochemical remediation of contaminated soils. J. Hazard. Mater. 195, 11-29. https://doi.org/10.1016/j.jhazmat.2011.08.047

Yeung, L.W.Y., De, S., Loi, E.I.H., Marvin, C.H., Taniyasu, S., Yamashita, N., Mabury, S.A., Muir, D.C.G., Lam, P.K.S., 2013. Perfluoroalkyl substances and extractable organic fluorine in surface sediments and cores from Lake Ontario. Environ. Int. 59, 389-397. https://doi.org/10.1016/j.envint.2013.06.026

Yusni, E.M., Tanaka, S., 2015. Removal behaviour of a thiazine, an azo and a triarylmethane dyes from polluted kaolinitic soil using electrokinetic remediation technology. Electrochimica Acta, 13th International Symposium on Electrokinetic Remediation (2014) 181, 130-138. https://doi.org/10.1016/j.electacta.2015.06.153

Zhi, Y., Liu, J., 2018. Sorption and desorption of anionic, cationic and zwitterionic polyfluoroalkyl substances by soil organic matter and pyrogenic carbonaceous materials. Chem. Eng. J. 346, 682-691. https://doi.org/10.1016/j.cej.2018.04.042 